\title{
Research progress on the ethanol precipitation process of traditional Chinese medicine
}

\author{
Yanni Tai, Jichen Shen, Yu Luo, Haibin Qu and Xingchu Gong (i)
}

\begin{abstract}
Ethanol precipitation is a purification process widely used in the purification of Chinese medicine concentrates. This article reviews the research progress on the process mechanism of ethanol precipitation, ethanol precipitation process application for bioactive component purification, ethanol precipitation and traditional Chinese medicine quality, ethanol precipitation equipment, critical parameters, parameter research methods, process modeling and calculation methods, and process monitoring technology. This review proposes that ethanol precipitation technology should be further developed in terms of five aspects, namely, an in-depth study of the mechanism, further study of the effects on traditional Chinese medicine quality, improvement of the quality control of concentrates, development of new process detection methods, and development of a complete intelligent set of equipment.
\end{abstract}

Keywords: Ethanol precipitation process, Critical process parameters, Optimization methods, Process modeling, Process monitoring technology

\section{Background}

In the 1950s, a batch of modern dosage forms of traditional Chinese medicine (TCM) appeared in the climax of national dosage form reform, such as tablets, capsules, injections, granules, and mixtures. To meet the higher refining requirements of these dosage forms for the TCM systems, water extraction and ethanol precipitation (EP) technologies have been widely used in the production of TCM. The ethanol precipitation process (EPP) has many advantages, such as simple operation, easy amplification, and solvent safety. The EPP can effectively remove highly polar molecules such as sugars, salts, and proteins, and it is beneficial to reduce the dosage [1]. In the production of TCM injections, multiple EP steps are often used to remove impurities entirely. Alkaline EP can remove tannins and further improve the safety of TCM injections

*Correspondence: gongxingchu@zju.edu.cn

Pharmaceutical Informatics Institute, College of Pharmaceutical Sciences,

Zhejiang University, Hangzhou 310058, Zhejiang, China
[2]. In the Chinese Pharmacopoeia (2015 Edition) [4], there were 274 kinds of Chinese herbal medicines involving EPP, accounting for $18.4 \%$ of the 1493 prescriptions and single formulations $[3,4]$. At present, the EPP also has disadvantages, including severe encapsulation loss, the low heat transfer efficiency of equipment, long standing time for precipitation, high energy consumption, and low efficiency of slag removal.

EP is often the first refining process or even the only refining process after the extraction of TCMs. The quality of the EPP has a significant impact on the difficulty of follow-up preparations and the quality of the final drug. In recent years, with the continuous improvement of Chinese medicine standards, the EPP has attracted much attention from academic and industrial circles. This article mainly reviews the research progress on the process mechanism of EPP, EPP application for bioactive component purification, EP and TCM quality, EP equipment, critical parameters, parameter research methods, process modeling and calculation methods, and process 
monitoring technology and proposes future development directions.

\section{EPP mechanism}

Generally, after adding ethanol to a TCM concentrate, the solubility of some strongly polar components and macromolecular components decreases in the system, causing precipitation. In a mixture of water and ethanol, the solubility of monosaccharides and oligosaccharides such as D-glucose, D-fructose, sucrose, maltose, raffinose, trehalose, and cyclodextrin has been reported [5-8]. Overall, the solubility of sugar components decreases with decreasing temperature or increasing ethanol content, which shows that properly increasing the ethanol concentration of the supernatant and lowering the standing temperature is beneficial to remove more sugar impurities. Bouchard et al. also reported solubility data of polysaccharides of inulin and dextran [5]. Ku et al. verified that polysaccharides with higher degree of polymerization were easier to precipitate in the mixed solvent of ethanol and water [9]. Boulet et al. found protein precipitated at different ratios when $\mathrm{pH}$ value varied in the mixture of ethanol and water. More protein precipitated as ethanol content in the mixed solvent increased [10].

There have been many studies on the solubility of TCM active components in water and ethanol. Partial solubility data are shown in Table 1. In general, the solubility of moderately polar active components in ethanol is generally higher than the solubility in water, indicating that these components theoretically will not precipitate during EPP.

However, the loss of active components during EPP has been observed by many researchers [30]. The authors believe that there are at least three reasons for the loss of active components, including encapsulation loss, precipitation loss, and degradation loss (Fig. 1). During EPP, the encapsulation loss can result from incomplete mixing of the ethanol and the concentrate, which can result in agglomeration and liquid encapsulation. Therefore, the coating phenomenon results in part of the active components not being dissolved in ethanol, leading to partial loss. The insufficient contact between ethanol and concentrate is caused by the large density difference between these solutions, the large viscosity of the concentrate, and the large amount of precipitate produced during EPP. Concentrate with higher dry matter content probably led to more encapsulation loss of active components [31]. The encapsulation loss is greatly affected by concentrate properties, EP equipment and operation conditions, and it will be reduced after a long standing time.

When the author studied the EPP of Danshen Chuanxiong mixed decoction concentrate [32], it was found

Table 1 Solubility of some TCM active components in water and ethanol

\begin{tabular}{|c|c|c|c|c|c|c|}
\hline Component category & Active component & Solubility in water & Solubility in ethanol & Unit of solubility & Temperature $/{ }^{\circ} \mathrm{C}$ & References \\
\hline \multirow[t]{3}{*}{ Phenolic acids } & Rosmarinic acid & $1.35 \times 10^{-2}$ & $2.68 \times 10^{-1}$ & $\mathrm{~mol} / \mathrm{mol}$ & 20 & [11] \\
\hline & Gallic acid & 1.07 & 23.7 & $\mathrm{~g} / 100 \mathrm{~g}$ & 25 & {$[12]$} \\
\hline & Gentisic acid & 2.20 & 45.5 & $\mathrm{~g} / 100 \mathrm{~g}$ & 25 & {$[12]$} \\
\hline \multirow[t]{5}{*}{ Phenols } & 2-Naphthol & 0.00 & $2.49 \times 10^{-1}$ & $\mathrm{~mol} / \mathrm{mol}$ & 20 & [13] \\
\hline & Catechol & $7.52 \times 10^{-2}$ & $3.57 \times 10^{-1}$ & $\mathrm{~mol} / \mathrm{mol}$ & 20 & [13] \\
\hline & Hydroquinone & $1.02 \times 10^{-2}$ & $1.88 \times 10^{-1}$ & $\mathrm{~mol} / \mathrm{mol}$ & 20 & [13] \\
\hline & Curcumin & $2.15 \times 10^{-8}$ & $6.62 \times 10^{-4}$ & $\mathrm{~mol} / \mathrm{mol}$ & 20 & [14] \\
\hline & trans-Resveratrol & $2.90 \times 10^{-6}$ & $1.56 \times 10^{-2}$ & $\mathrm{~mol} / \mathrm{mol}$ & 20 & [15] \\
\hline \multirow[t]{11}{*}{ Flavonoids } & Apigenin & $7.00 \times 10^{-7}$ & $2.44 \times 10^{-4}$ & $\mathrm{~mol} / \mathrm{mol}$ & 15 & [16] \\
\hline & Baicalein & $6.63 \times 10^{-6}$ & $1.04 \times 10^{-3}$ & $\mathrm{~mol} / \mathrm{mol}$ & 20 & [17] \\
\hline & Chrysin & $1.26 \times 10^{-5}$ & $6.89 \times 10^{-3}$ & $\mathrm{~mol} / \mathrm{mol}$ & 20 & {$[18]$} \\
\hline & Genistein & $5.30 \times 10^{-6}$ & $3.74 \times 10^{-2}$ & $\mathrm{~mol} / \mathrm{L}$ & 25 & [19] \\
\hline & Luteolin & $1.75 \times 10^{-6}$ & $1.88 \times 10^{-3}$ & $\mathrm{~mol} / \mathrm{mol}$ & 25 & {$[20]$} \\
\hline & Hesperetin & $2.40 \times 10^{-6}$ & $7.30 \times 10^{-2}$ & $\mathrm{~mol} / \mathrm{L}$ & 20 & [21] \\
\hline & Hesperidin & $1.42 \times 10^{-7}$ & $3.08 \times 10^{-5}$ & $\mathrm{~mol} / \mathrm{mol}$ & 20 & {$[22]$} \\
\hline & Naringenin & $6.62 \times 10^{-7}$ & $9.20 \times 10^{-3}$ & $\mathrm{~mol} / \mathrm{mol}$ & 20 & [23] \\
\hline & Naringin & $9.76 \times 10^{-7}$ & $3.98 \times 10^{-5}$ & $\mathrm{~mol} / \mathrm{mol}$ & 20 & [24] \\
\hline & Daidzin & $4.10 \times 10^{-6}$ & $3.97 \times 10^{-4}$ & $\mathrm{~mol} / \mathrm{mol}$ & 20 & {$[25]$} \\
\hline & Daidzein & $6.08 \times 10^{-8}$ & $2.70 \times 10^{-4}$ & $\mathrm{~mol} / \mathrm{mol}$ & 20 & {$[26]$} \\
\hline Alkaloids & Piperine & $1.07 \times 10^{-5}$ & $8.99 \times 10^{-3}$ & $\mathrm{~mol} / \mathrm{mol}$ & 25 & {$[27]$} \\
\hline \multirow[t]{2}{*}{ Coumarins } & Osthole & $4.86 \times 10^{-7}$ & $1.75 \times 10^{-2}$ & $\mathrm{~mol} / \mathrm{mol}$ & 20 & [28] \\
\hline & Isoimperatorin & $7.42 \times 10^{-7}$ & $3.77 \times 10^{-3}$ & $\mathrm{~mol} / \mathrm{mol}$ & 20 & [29] \\
\hline
\end{tabular}


a

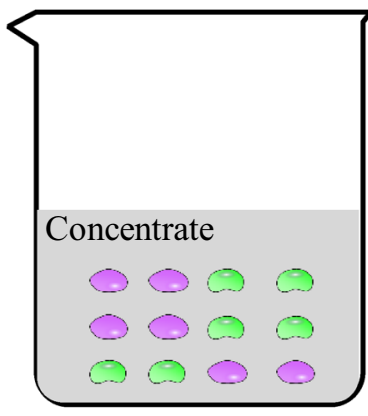

b

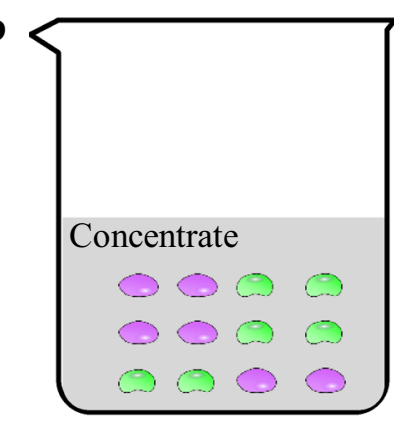

c

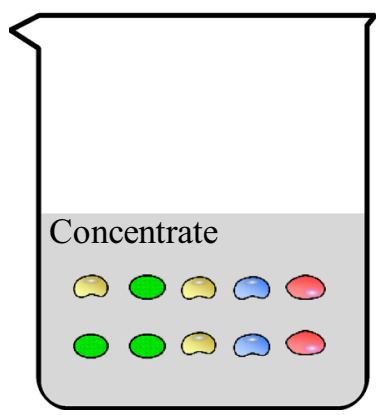

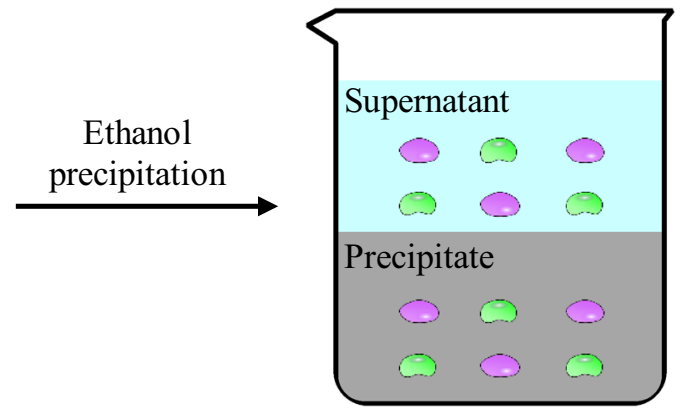
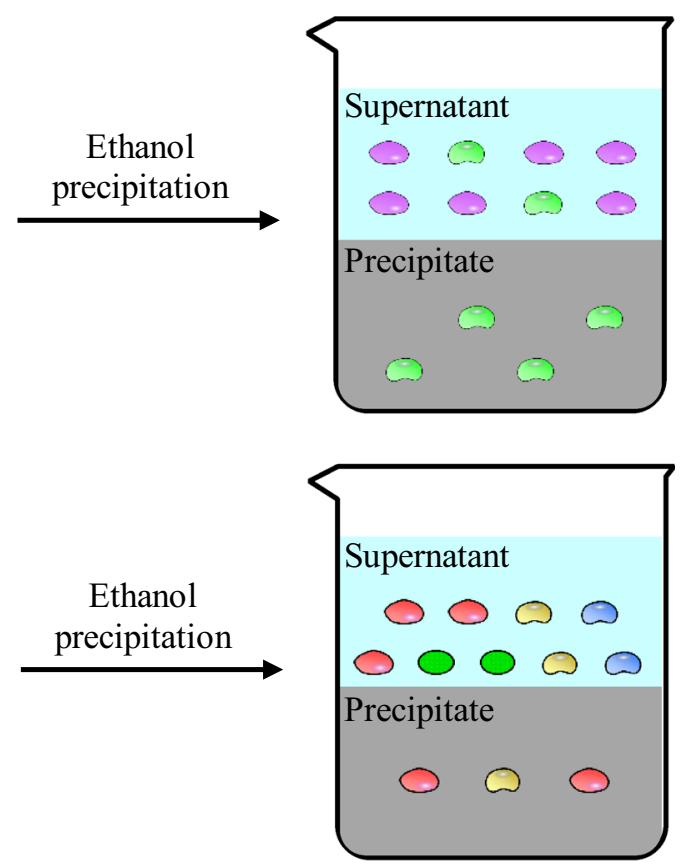

Active components with large solubility in supernatant

Active components with small solubility in supernatant

$\bigcirc$ Active components generated in EPP

Active components degraded in EPP

$\bigcirc \bigcirc$ Active components without degradation in EPP

a Encapsulation loss. b Precipitation loss. c Degradation loss.

Fig. 1 Loss mechanism of active components

that the total content of danshensu and salvianolic acid $B$ in the supernatant and precipitation after EPP was less than the total amount in the concentrate. However, the content of lithospermic acid in the supernatant and precipitation was significantly higher than that in the concentrate. This phenomenon indicates that the active components may be degraded or polymerized in the supernatant, resulting in degradation loss.

The dissociation constant values of salvianolic acids in several liquid-liquid equilibrium systems were determined [33], which verified that phenolic acids often exist in medicinal plants in the form of phenolic acid salts according to the $\mathrm{pH}$ value of concentrate. The solubility 
of phenolic acid salts in the supernatant is usually lower than that of phenolic acid molecules, which is the reason for the precipitation loss of phenolic acids.

Three types of active component loss may exist simultaneously in an EPP. Degradation loss can be determined by comparing the total amount of an active component before and after EPP. For an active component with large solubility in the mixed solvent of water and ethanol, encapsulation loss probably exists when some of this active component is found in the precipitate. However, it is still difficult to distinguish between precipitation loss and encapsulation loss when the solubility of the active component is not very large.

\section{EPP application for bioactive component purification}

EPP is a conventional purification technology for bioactive components in TCMs, such as alkaloids, flavonoids [30], anthraquinones [34], organic acids, polysaccharides, and proteins. Polysaccharides and proteins are usually collected from the precipitate of EPP. The polysaccharides of TCMs may possess antioxidant activity [35, 36], anti-tumor activity [37], immunomodulatory effects [38], and hepatoprotective effect [39]. By adjusting the ethanol concentration in supernatant, polysaccharides with different molecular weight distributions can be obtained. The general rule is that higher ethanol concentration in supernatant results in the precipitation of polysaccharides with smaller molecular weights. Therefore, EPP is also widely used in the grading of polysaccharides [40]. Alkaloids, flavonoids, organic acids, saponins, or other active components of TCMs are usually enriched in the supernatant after EPP. At most occasions, a mixture of these active components and other components is prepared. Therefore, EPP is used to prepare the so-called "total alkaloids", "total flavonoids", "total phenolic acids", or "total saponins". EPP is also reported in the precipitation of plant DNA [41], especially in the DNA barcoding identification of Chinese medicinal materials.

\section{EP and TCM quality}

In order to ensure the safety and effectiveness of TCMs, pharmacodynamic indices are widely used in the research of the manufacturing processes of TCMs. Compared with physical and chemical indices, pharmacodynamic indices can reflect the efficacy as a whole for TCMs. Some works on the relationship between EPP and pharmacodynamic indices are listed in Table 2. There are more than ten pharmacodynamic indices were reported in the evaluation of EP products, such as analgesic effect, anti-hypertensive effect, antipyretic, anti-inflammator, and so on.

Many researchers found that pharmacodynamic indices changed little after EPP. It indicated that EPP could probably reduce daily dosage of the preparation without lowering its efficacy. Drug efficacy was significantly enhanced after EPP in some published works [50, 52, 54]. It means that active components were enriched after EPP. Some researchers found that pharmacodynamic indices remarkably improved when the apparent content of ethanol reached about $75 \%[50,54]$. However, Du et al. observed that its effects of improving sleep are weakened after EPP [55]. The possible reason was that some active components lost in EPP because of precipitation, degradation, or encapsulation. The active components lost in EPP may possess a direct or synergistic drug efficacy.

Table 2 Relationship between EPP and pharmacodynamic indices

\begin{tabular}{|c|c|c|}
\hline Medicinal materials or compound preparations & The pharmacodynamic index changes after EPP & References \\
\hline Wubie granule intermediates & No significant difference & {$[42]$} \\
\hline Yanshuning compound & No significant difference & {$[43]$} \\
\hline Zhuang Medicine Baijin granules & No significant difference & {$[44]$} \\
\hline Dingtongning granules & No significant difference & {$[45]$} \\
\hline Changkang granules & No significant difference & {$[46]$} \\
\hline Eryan Huguo decoction & No significant difference & {$[47]$} \\
\hline Xikebao decoction & No significant difference & {$[48]$} \\
\hline Shenqi Sherong pills & No significant difference & {$[49]$} \\
\hline Gualou-Xiebai extracts & Antioxidant activity was enhanced & {$[50]$} \\
\hline Lidan Paidu prescription & No significant difference & {$[51]$} \\
\hline Prunella vulgari & Anti-hypertensive effect was enhanced & {$[52]$} \\
\hline Scutellariae radix extract & $\begin{array}{l}\text { After EP twice, antipyretic and anti-inflammatory effects were weakened } \\
\text { compared with EP once }\end{array}$ & {$[53]$} \\
\hline Chimonobambusa quadrangularis & Antioxidant activity was enhanced & {$[54]$} \\
\hline Guizhi Zhumian capsule & Sleep improvement function was reduced & [55] \\
\hline
\end{tabular}


Overall, most works showed that EPP can reduce daily dosage of TCM preparation without significantly lower drug efficacy. However, EPP is not suitable for some TCMs. Ethanol content in EP supernatant should be optimized for keeping or enhancing drug efficacy.

\section{EP equipment}

EPP is commonly carried out in an EP tank in the industry, and its schematic diagram is shown in Fig. 2. The concentrate and ethanol in the EP tank can be mixed either by mechanical agitation or air agitation; the former is widely used [56]. The advantage of air agitation in an EP tank is that there are no moving parts in the tank, and the possibility of equipment failure is slight. The disadvantage is that the air will cause evaporation and loss of ethanol [57]. If the EP tank is provided with a jacket, it can be cooled by refrigerating with low-temperature liquid. If the EP tank is not provided with a jacket, it can be moved into a refrigerated room for refrigeration. After the EP supernatant is collected, the EP precipitation is discharged from the slag outlet.

At present, the main improvement directions of EP equipment are to improve the mixing effect of the concentrate and ethanol and to reduce the difficulty of slagging after EPP. The authors used a micromixer to continuously mix the concentrate and ethanol to achieve a continuous steady-state process during the ethanol addition process (Fig. 3) [58]. This method can be used to control the amount of ethanol addition

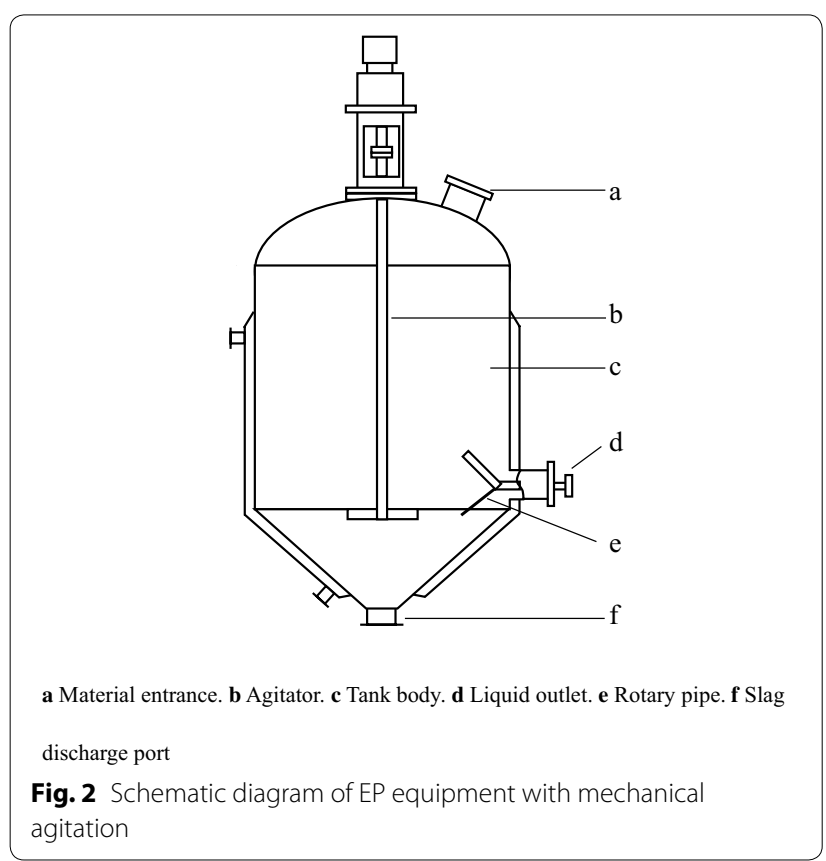

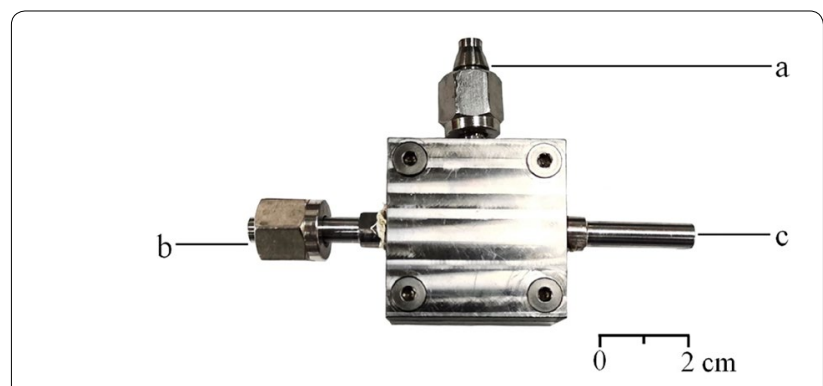

a Ethanol solution; b Concentrate; c Outlet

Fig. 3 The appearance of EP micromixer

by adjusting the flowrates of ethanol and concentrate. The encapsulation loss of active components were also effectively reduced [31]. In conventional equipment, ethanol is added slowly and stirred quickly to reduce encapsulation loss. For the micromixer, the faster the ethanol is added, the better the mixing effect, and time can be saved. Yu et al. [59] used a pressure-type mechanical atomization device to atomize the concentrate and ethanol to improve mixing effect. Changing the position of the agitator or improving the structure of the paddle can also improve the mixing effect [60, 61 . Adding a shear agitator and a slag outlet at the bottom of the EP tank can reduce manually clean precipitation and improve the efficiency of slag removal [62]. These improved EP equipment will be more widely used in the future.

\section{Critical parameters and optimization methods of the EPP}

Table 3 lists the experimental design methods, optimization goals, and critical factors, based on more than 70 studies reported about the EPP in the past 10 years. Researchers mainly use single factor design, orthogonal design, fractional factorial design, and Plackett-Burman design to determine the critical factors of EPP. Compared with single factor design and orthogonal design, fractional factorial design and Plackett-Burman design can use only a few experiments to explore the influence of many parameters.

The frequency of each critical factor in Table 3 is listed in Table 4. Several factors, such as the density, concentration ratio, concentration, water content, and solid content of the concentrate, can reflect the amount ratio between the solid and solvent in the concentrate. Lower solvent content of concentrate, higher amount of ethanol, and higher concentration of ethanol all lead to a higher ethanol content of the EP supernatant. The ethanol content of EP supernatant affects the solubility of the components 


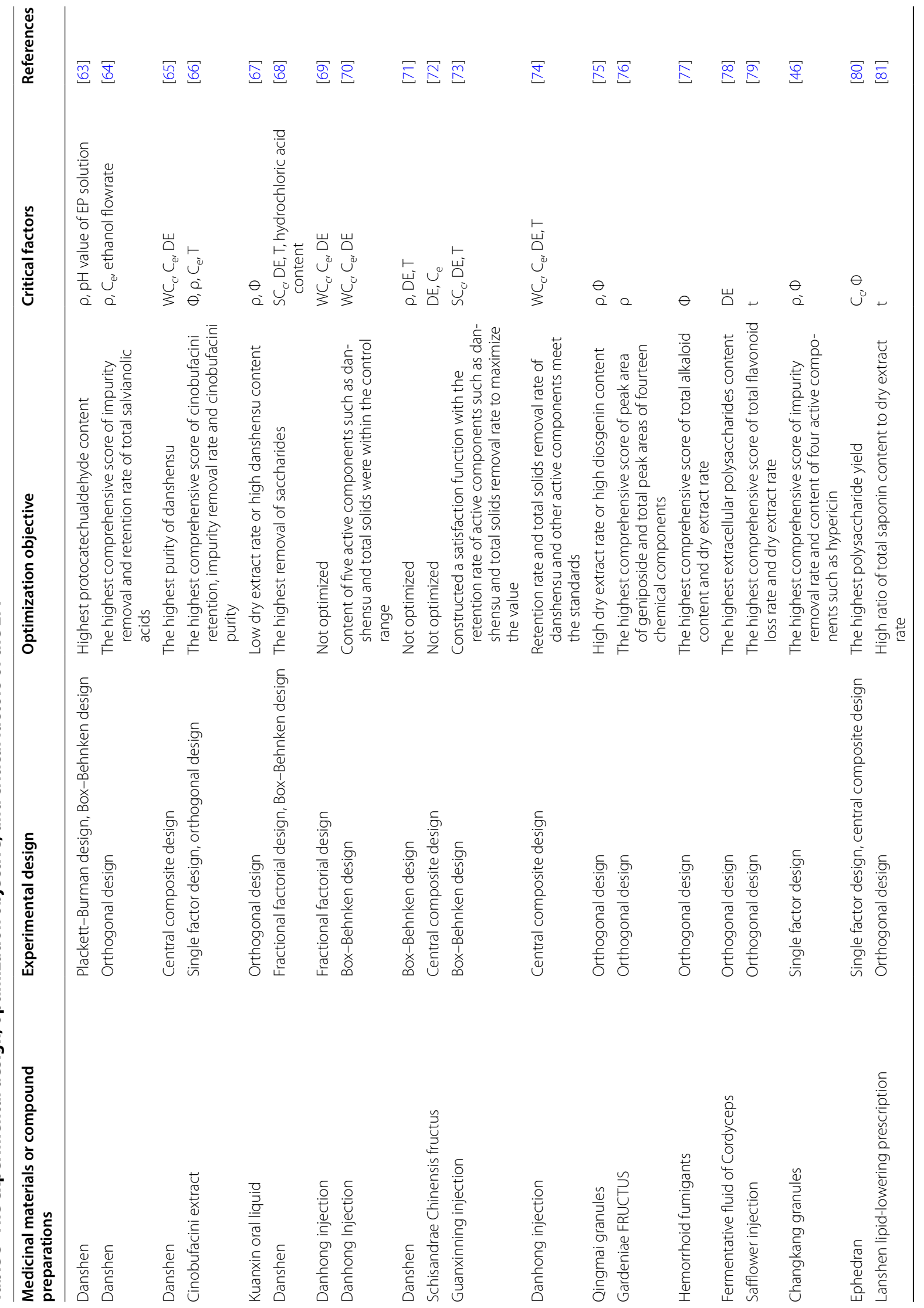




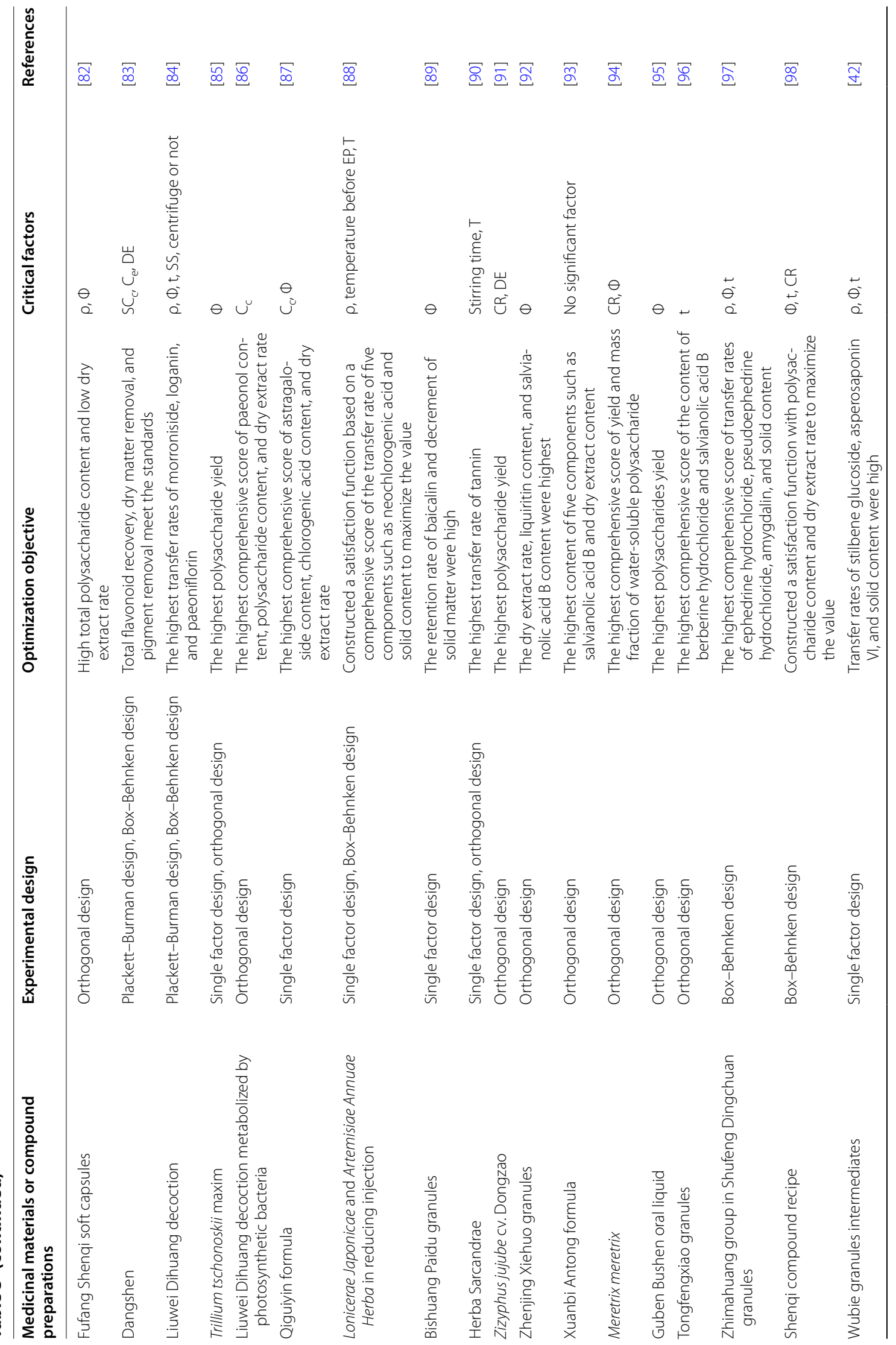




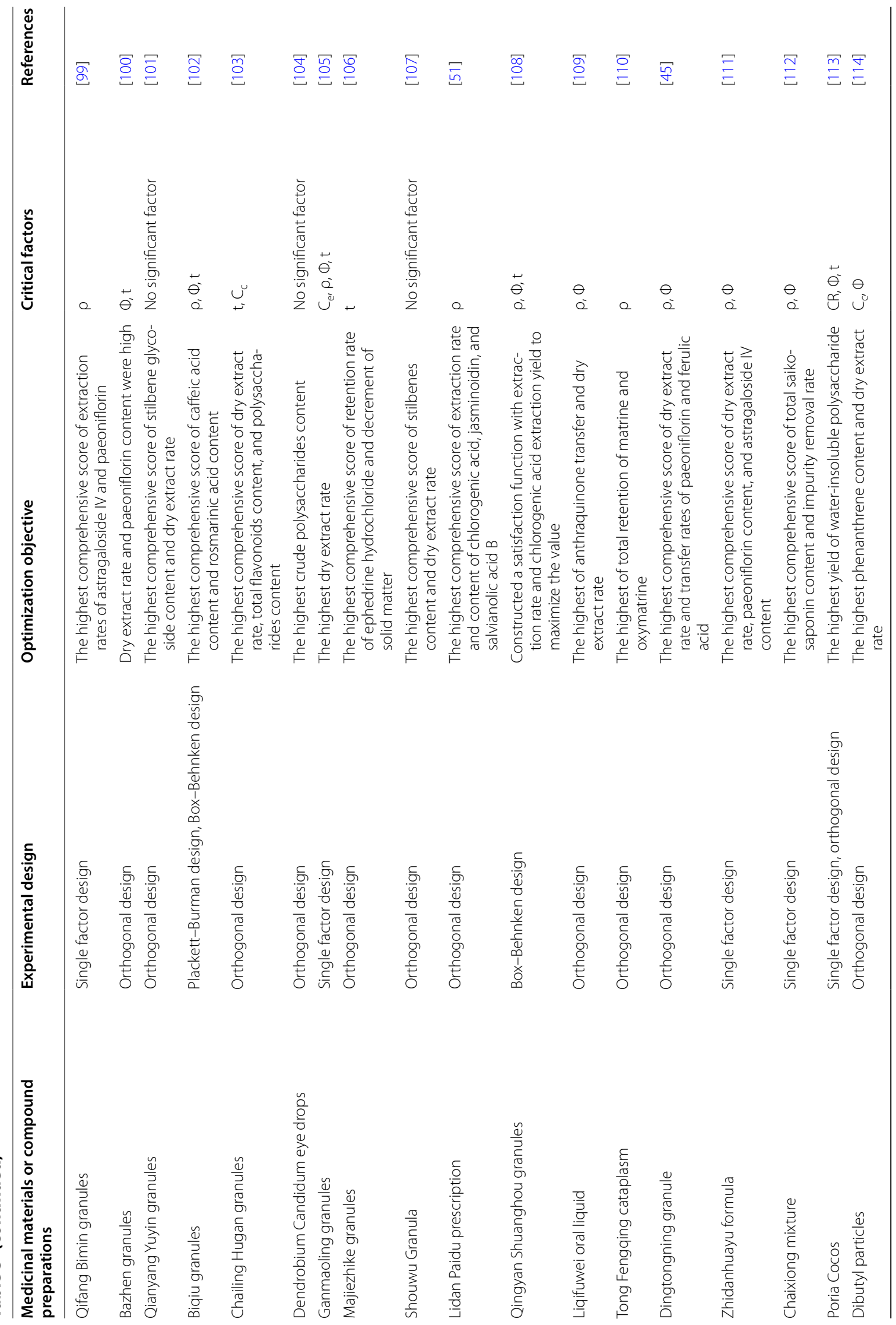




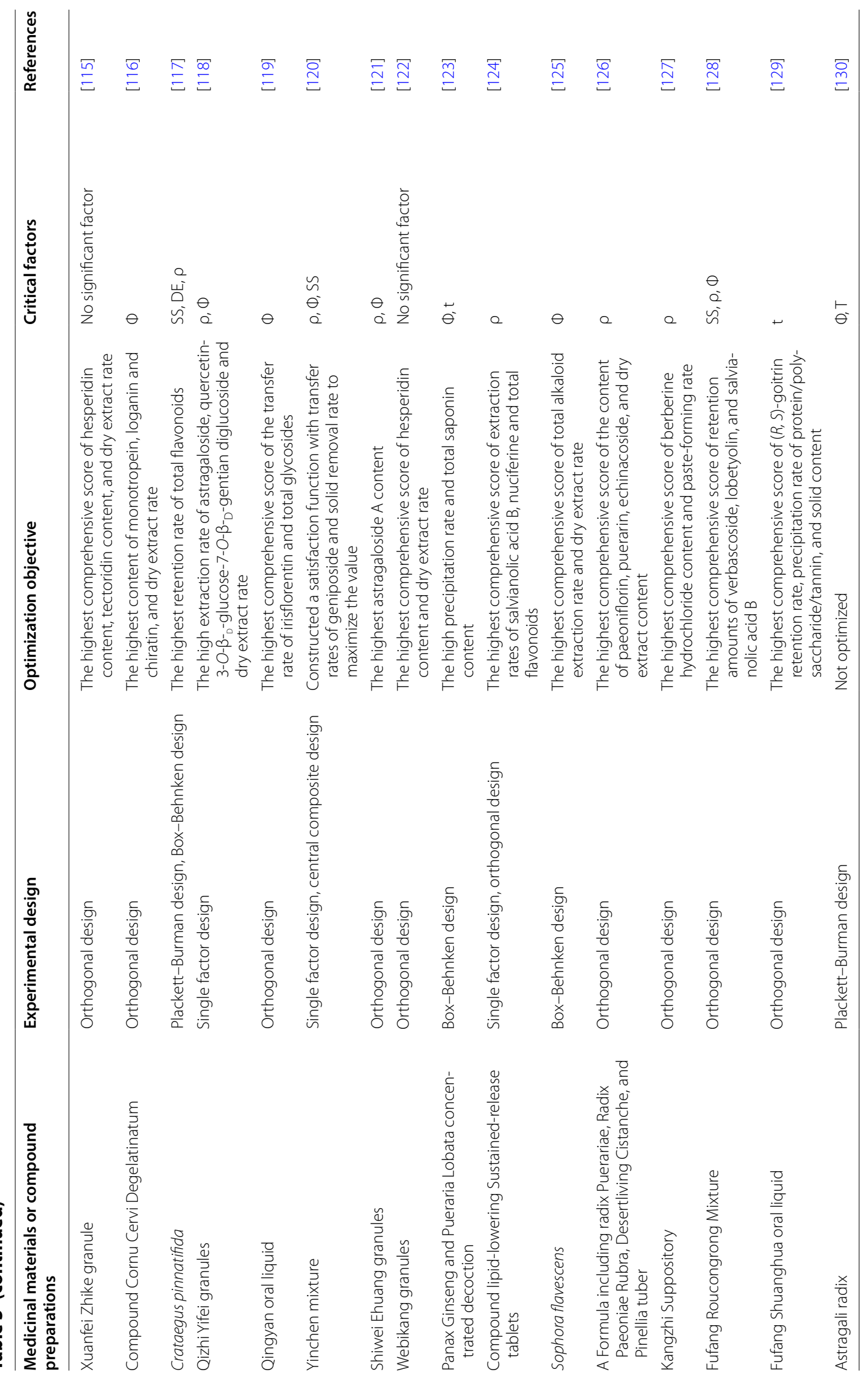




\section{Table 4 The frequency of critical factors}

\begin{tabular}{lll}
\hline No. & Critical factors & Research frequency \\
\hline 1 & D & 36 \\
2 & 0 & 31 \\
3 & $\mathrm{t}$ & 16 \\
4 & $\mathrm{DE}$ & 12 \\
5 & $\mathrm{C}_{\mathrm{e}}$ & 9 \\
6 & $\mathrm{~T}$ & 8 \\
7 & $\mathrm{C}_{\mathrm{c}}$ & 5 \\
8 & $\mathrm{CR}$ & 4 \\
9 & $\mathrm{SS}$ & 4 \\
10 & $\mathrm{WC}_{\mathrm{c}}$ & 4 \\
11 & $\mathrm{SC}_{\mathrm{c}}$ & 3 \\
12 & Others & 6 \\
\hline
\end{tabular}

in the concentrate, so the above factors are often critical. The standing temperature is also often considered a critical parameter, mainly because temperature affects solubility. In a few pieces of literature, the stirring speed and ethanol flowrate are also considered critical parameters. From the above mechanism analysis, it can be seen that when the concentration of concentrate is high, it is difficult to mix the ethanol and concentrate completely. A high stirring speed or slow ethanol flow rate is favorable for mixing, so it may also become a critical parameter. Many researchers have found that the standing time also has a significant effect on the effect of EPP, probably because the concentrate encapsulated in the precipitate can gradually dissolve after standing for a long time, thereby changing the composition of the supernatant.

According to the researches shown in Table 3, the Ishikawa diagram of the EPP was sorted out, as shown in Fig. 4. This diagram involves many factors, such as ethanol, concentrate, ethanol addition, environment, equipment, standing, and stirring.

Many studies have considered the density, water content, and solid content of the concentrate. However, the differences between different batches of concentrate are mainly reflected in the content of each component in the total solid and other physical and chemical properties except density. There are few studies on these factors. Zhang et al. [131] screened out the critical properties of the concentrate of the first EP of Danshen injection by stepwise regression and partial least square method. The results showed that the $\mathrm{pH}$ and caffeic acid content of the concentrate are the critical parameters affecting the phenolic acid content in the supernatant of the second EPP. Furthermore, Yan et al. [132] found that the retention rate of phenolic acids in the second EPP of Guanxinning injection was mainly affected by the contents of danshensu, caffeic acid, and salvianolic acid B in the concentrated supernatant of the first EPP. These research findings further indicate that the quality of the supernatant is affected by the properties of EP raw materials.

There are many process parameters or concentrate properties that may affect EP results. However, the parameters of EPP are usually limited in narrow ranges in industry. Therefore, the quality control of concentrates is very important to keep batch-to-batch consistency of supernatants. By improving the quality control of decoction pieces and upstream processes of EPP, the quality of concentrate can be controlled within a proper range to promote the quality of the EPP.

\section{Modeling and calculation of the EPP Semimechanical modeling}

Assuming that the concentrate is composed of water and total solids, there is no water in EP precipitation, and the mass fraction $(\phi)$ of ethanol in the supernatant solvent is defined in Eq. (1) [73]:

$$
\phi=\frac{E C_{e} \times E C R}{W C_{c}+E C R}
$$

where $E C_{e}$ refers to the mass fraction of ethanol used in EPP, $E C R$ refers to the mass ratio of ethanol and the concentrate, and $W C_{c}$ refers to the water content of the concentrate. The content of saturated components in the supernatant is also their solubility $(S)$, which is defined in Eq. (2) [32]:

$$
S=S_{w} \times(1-\phi)^{\alpha}
$$

where $S_{w}$ refers to the solubility of the component in pure water, and $\alpha$ refers to the parameter to be fitted.

Organic acids may exist in EP systems in molecular form and salt form. If precipitation loss occurs, it may be because the organic acid salts are saturated in the supernatant. The relationship between the $p K_{a}$ value, the solubility of the organic acid salt $\left(S_{A}\right)$, the $p H$ of the supernatant, the total concentration $\left(C_{A}\right)$ of the organic acid and organic acid salts in the supernatant is shown in Eq. (3), which can also be used to calibrate the $p K a$ value of phenolic acid and solubility of phenolic acid salts [32].

$$
\frac{C_{A}}{S_{A}}=10^{\left(p K_{a}-p H\right)}+1
$$

Till now, the mechanism research of EPP is not indepth. Accordingly, the current semimechanical models are relatively simple. There are no reports on mechanism model of EPP.

\section{Statistical modeling}

Single factor design, orthogonal design, central composite design, and Box-Behnken design are often used to 
optimize the parameters of the EPP. Compared with single factor design, response surface design can consider the interaction between factors. With the same number of factors, response surface design has more experiments than orthogonal design. Still, after modeling, response surface design can obtain the optimal global condition in the research scope. Central composite design and BoxBehnken design usually adopt polynomial modeling after obtaining the experimental data. The form is as follows Eq. (4):

$$
\begin{aligned}
Y= & b_{0}+\sum_{i=1}^{m} b_{i} X_{i}+\sum_{i=1}^{m} b_{i i} X_{i}^{2} \\
& +\sum_{i=1}^{m-1} \sum_{i=i+1}^{m} b_{i j} X_{i} X_{j}
\end{aligned}
$$

where $Y$ refers to the evaluation index of the EPP, $b_{0}$ refers to a constant term, $b_{\mathrm{i}}, b_{\mathrm{ii}}$, and $b_{\mathrm{ij}}$ refer to regression coefficients, and $m$ refers to the number of factors in the experimental design. The quality of the EPP can be evaluated by the index component content, component retention rate, impurity removal rate, total solid removal rate, and pharmacodynamic index [102]. Modeling can be simplified by using methods such as stepwise regression. Polynomial models are easy to build and explain. However, the models are difficult to be extended to another EP equipment or another batch of concentrate.

\section{Parameter optimization calculation}

The largest multi-index comprehensive score, largest satisfaction function value, and all indexes falling within the preset ranges are commonly used optimization objectives. The multi-index comprehensive scoring method and the satisfaction function can be used to address different dimensions of process evaluation indicators, but the subjectivity is large when determining weights. When there is a strong correlation between the evaluation indexes of the EPP, the use of the satisfaction function should be carefully performed [133]. A group of optimal parameter combinations is often obtained to maximize the comprehensive score of multiple indicators or the satisfaction function. Nevertheless, this approach is not conducive to flexible adjustment of process parameters in the actual production of multiple batches.

When using all the indexes that fall into the preset ranges as the parameter optimization target, the optimized process parameter ranges can be calculated generally. This research method is in line with the design space concept of quality by design (QbD) [134]. The parameter variation within the design space is not considered as a process change, so the approach is beneficial to pharmaceutical companies not only to increase production flexibility but also to reduce unnecessary supervision. The optimal parameter range can be obtained by using the overlapping method and the probability-based method [135]. The probability-based method quantifies the assurance of EPP quality with probability values in the optimization of parameter ranges. The probability values calculated by the experimental error simulation method [135] and the parameter disturbance simulation method [136] are more accurate.

Yan et al. established a mathematical model between the contents of active components in concentrates, the process parameters, and the properties of supernatant by adopting a feedforward control strategy. Then, according to the contents of active components in the concentrate, the parameters of the EPP of Danhong injection were adjusted. This method can improve the consistency of the active component contents in the supernatant [70]. The authors noticed that the refrigeration temperature for EP in the production of pharmaceutical companies is affected by the season. Therefore, it is proposed to set the refrigeration temperature as the noise parameter and optimize the range of other easily controlled parameters to reduce the impact of noise parameter fluctuation [74].

Operating process parameters with design space, varying process parameters according to the change of concentrate quality, or adjusting controllable parameters to lower the effects of noise parameters can all improve the batch-to-batch consistency of supernatant quality after EPP.

\section{The monitoring method of the EPP}

In the production of TCM, an ethanol meter is widely used to detect the apparent ethanol content of the supernatants on the spot. This method is simple and practical, but only the density information of the liquid can be obtained.

The monitoring technology and indicators of EPP in the literature are listed in Table 5. At present, near-infrared spectroscopy (NIR) is widely used due to its simple sample preprocessing, fast speed, losslessness, large amount of information collected, etc. In general, partial least square regression and other methods can be used to correlate the NIR information with the contents of index components/major components in the supernatant. Spectral preprocessing methods have a great influence on the modeling results. Common preprocessing methods include standard normal variate, multiplicative scatter correction, Savitzky-Golay smoothing, NorrisWilliams smoothing, first derivative, second derivative, etc. By establishing a multivariate statistical process control model, the control limit of the process operation statistics (such as Hotelling $\mathrm{T}^{2}$, squared prediction error, and principal component score) is set up, and the process trajectory diagram is drawn. The multivariate statistical process control model can monitor the EPP in real-time 


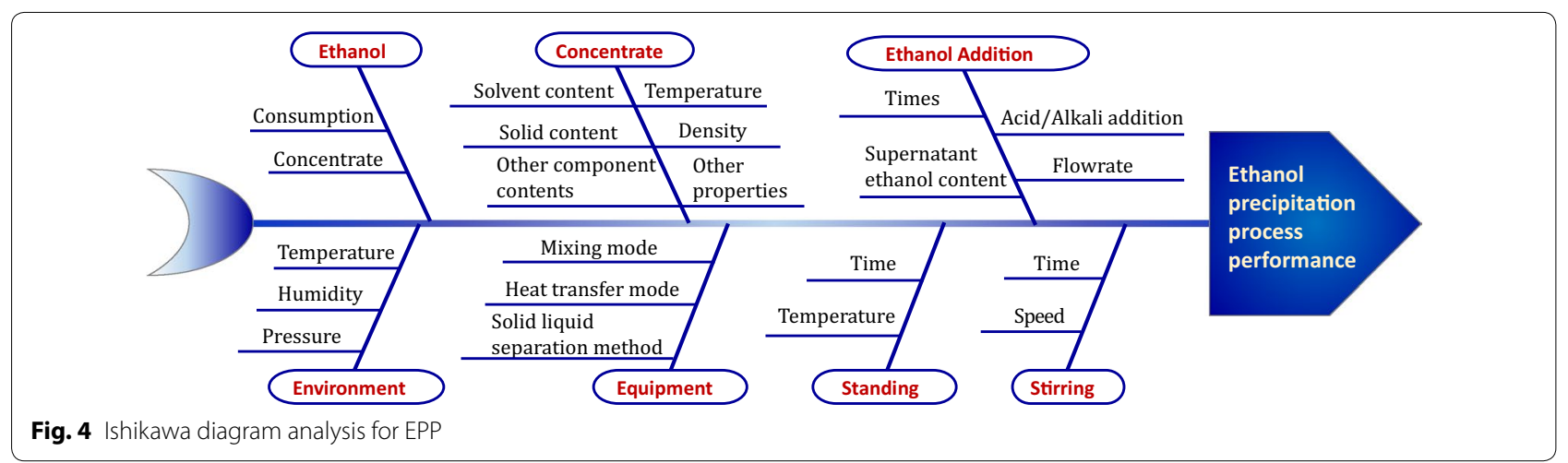

Table 5 The monitoring technology and process indicators of EP

\begin{tabular}{|c|c|c|c|}
\hline $\begin{array}{l}\text { Medicinal materials } \\
\text { or compound preparations }\end{array}$ & $\begin{array}{l}\text { Detection } \\
\text { technology }\end{array}$ & Monitoring indexes & References \\
\hline Danshen & NIR & The concentration of danshensu and protocatechualdehyde, and total solid content & {$[137]$} \\
\hline Danshen & NIR & $\begin{array}{l}\text { The concentration of six active components such as danshensu, solid content, scores of } \\
\text { the first principal component, Hotelling } T^{2} \text {, squared prediction error }\end{array}$ & {$[138]$} \\
\hline Rukuaxiaopian & NIR & The concentration of danshensu and hesperidin & [139] \\
\hline Danshen & NIR & Tannin concentration & {$[140]$} \\
\hline Danshen & NIR & Scores of the first principal component, Hotelling $\mathrm{T}^{2}$, squared prediction error & {$[141]$} \\
\hline Cinobufacini & NIR & Indole alkaloids concentration & [142] \\
\hline Lonicerae Japonicae & NIR & Hotelling $T^{2}$, squared prediction error & {$[143]$} \\
\hline Lonicerae Japonicae & NIR & Chlorogenic acid concentration & {$[144]$} \\
\hline Lonicerae Japonicae & NIR & Chlorogenic acid concentration & {$[145]$} \\
\hline Danhong Injection & NIR & Solid content and concentration of five active components such as danshensu & {$[146]$} \\
\hline Reduning Injection & NIR & The concentration of four active components such as neochlorogenic acid & {$[147]$} \\
\hline Reduning Injection & NIR & The concentration of chlorogenic acid and solid content & {$[148]$} \\
\hline Shenzhiling Oral Solution & NIR & The concentration of six active components such as paeoniflorin & {$[149]$} \\
\hline Dangshen & NIR & The concentration of lobetyolin, total flavonoids, pigments, and total solid contents & {$[150]$} \\
\hline Astragali Radix & NIR & $\begin{array}{l}\text { Scores of the first principal component, Hotelling } \mathrm{T}^{2} \text {, squared prediction error, the con- } \\
\text { centration of six active components, and total solid content }\end{array}$ & [151] \\
\hline Danshen & NIR & The concentration of glucose, fructose, and sucrose & {$[152]$} \\
\hline
\end{tabular}

and sensitively judge the normal operation state of the process. The establishment of a multivariate statistical process control model is helpful further to implement the feedback control of the EPP.

In general, spectrum of EP system is rich in information. The process monitoring method based on spectrum can not only judge the process state, but also quantify the concentrations of specific components in combination with chemometrics.

\section{Conclusions and perspective}

Based on the extensive review, great progress has been made in the study of process parameters, optimization methods, and process monitoring methods of EP of TCM. Problems still exist in industrial EP, including the loss of active components, the long time necessary for refrigeration, the quality difference between batches of EP supernatants, etc. In the future, EP technology research can be carried out from the following directions:

\section{Further study on the mechanism of EP}

The difference in concentrates between batches is mainly reflected in the fluctuation of the content of the components. At present, there have been reports about the influence of ethanol content in the supernatant on the solubility of Chinese herbal medicinal components. Nevertheless, there is no study on the influence of the content of Chinese herbal medicinal components on the solubility of other components. Therefore, it is not yet possible to describe the effect of the composition change 
of concentrate on the effect of EP. It is also difficult to accurately predict the material transfer and drug delivery rule of EPP.

\section{Further study on the effects of EP on TCM quality}

EPP is widely used in TCM industry from the last century. However, the quantitative effects of EPP on TCM quality are still unclear. The relationship between TCM substances and its quality is generally nonlinear. Therefore, some newly developed artificial intelligence technology can probably be used for the investigation of EPP and TCM quality. For example, as a typical algorithm of deep learning, convolutional neural network $(\mathrm{CNN})$ can be a useful tool to deal with nonlinear quantitative problems [153, 154].

\section{Establish a stricter quality control method for concentrates} At present, the concentrate quality in the industry is mostly controlled by density or volume. However, less attention has been paid to the chemical composition of the concentrate. It is recommended that the concentrate be used as one of the critical intermediates, and the quality standard of its composition should be set. Yan et al. used the quantitative model of process parameters, raw material properties, and EP evaluation index to backcalculate the quality standard of a concentrate [155]. This work provides a scientifically based method to set the quality standard of the concentrates. Where permitted by regulations, it can be considered that EP can be carried out after a mixed concentrate is prepared with different batch concentrates, which will help to improve the consistency of the components of the supernatant.

\section{Enrich the detection technology of the EPP}

NIR combined with multivariate statistical analysis is used to detect indicators/major components or to detect process trajectories. NIR has many advantages, but the equipment cost is high, and the renewal and maintenance of the multivariate statistical model require professionals. In addition, there is still no means to detect the amount of encapsulation loss. Therefore, it is still necessary to develop simpler and easier-to-use detection technology.

\section{Develop high-efficiency digital ethanol precipitation equipment}

At present, the structure of EP equipment is simple, and process control relies heavily on manual work. The energy and material consumption are still high. Therefore, a complete set of intelligent EP equipment should be developed based on multidisciplinary technology. This equipment should be able to improve the efficiency of heat and mass transfer, quickly collect and analyze process data, and realize the automatic control of EPP.

\begin{abstract}
Abbreviations
TCM: Traditional Chinese medicine; EP: Ethanol precipitation; EPP: Ethanol precipitation process; NIR: Near-infrared spectroscopy; $p$ : Density of concentrate; $\mathrm{C}_{c}$ : Concentration of concentrate; $\mathrm{SC}_{c}$ : Solid content of concentrated supernatant; WC. Water content of concentrated extract; DE: Ethanol consumption;

$C_{e}$ : Ethanol concentration; $\Phi$ : Ethanol content of ethanol precipitate; $T$ : Ethanol precipitation temperature; t: Ethanol precipitation time; SS: Stirring speed; CR: Concentration ratio.
\end{abstract}

\section{Acknowledgements}

Not applicable.

\section{Authors' contributions}

YNT and JCS conducted literature searches, drafted the manuscript, and prepared tables and figures; $Y L$ drafted the manuscript and prepared tables; $\mathrm{HBQ}$ revised the review; XCG conceived and designed the review, and finally confirmed the manuscript. All authors read and approved the final manuscript.

\section{Funding}

The authors would like to acknowledge the support of the National S\&T Major Project of China (2018ZX09201011-002), the Basic Public Welfare Research Program of Zhejiang Province (LGG18H280001), and the National Project for Standardization of Chinese Materia Medica (ZYBZH-C-GD-04).

Availability of data and materials

All reported or analyzed data in this review are extracted from published articles.

Ethics approval and consent to participate Not applicable.

\section{Consent for publication}

Not applicable.

\section{Competing interests}

The authors declare that they have no competing interests.

Received: 3 May 2020 Accepted: 3 August 2020

Published online: 10 August 2020

References

1. Gong XC, Wang SS, Qu HB. Comparison of two separation technologies applied in the manufacture of botanical injections: second ethanol precipitation and solvent extraction. Ind Eng Chem Res. 2011;50(12):7542-8.

2. Gong XC, Li Y, Qu HB. Removing tannins from medicinal plant extracts using an alkaline ethanol precipitation process: a case study of Danshen injection. Molecules. 2014;19(11):18705-20.

3. Shao F, Yu MY, Jiang ML, Yang M, Shang Y, Liu RH, et al. Establishment of determination of fractal dimension of ethanol-precipitated flocs of two root medicinal herbs. Chin J Exp Med Formul. 2019;25(22):103-7 (in Chinese).

4. State Pharmacopoeia Commission. Pharmacopoeia of the People's Republic of China, vol. 1. Beijing: China Medical Science Press; 2015.

5. Bouchard A, Hofland GW, Witkamp GJ. Properties of sugar, polyol, and polysaccharide water-ethanol solutions. J Chem Eng Data. 2007;52(5):1838-42.

6. Gong XC, Wang SS, Qu HB. Solid-liquid equilibria of D-glucose, D-fructose and sucrose in the mixture of ethanol and water from $273.2 \mathrm{~K}$ to 293.2 K. Chin J Chem Eng. 2011;19(2):217-22.

7. Gong XC, Wang C, Zhang L, Qu HB. Solubility of xylose, mannose, maltose monohydrate, and trehalose dihydrate in ethanol-water solutions. J Chem Eng Data. 2012;57(11):3264-9. 
8. Zhang L, Gong XC, Wang YF, Qu HB. Solubilities of protocatechuic aldehyde, caffeic acid, D-galactose, and D-raffinose pentahydrate in ethanol-water solutions. J Chem Eng Data. 2012;57(7):2018-22.

9. Ku Y, Jansen O, Oles CJ, Lazar EZ, Rader Jl. Precipitation of inulins and oligoglucoses by ethanol and other solvents. Food Chem. 2003;81(1):125-32.

10. Boulet M, Britten M, Lamarche F. Dispersion of food proteins in wateralcohol mixed dispersants. Food Chem. 2001;74(1):69-74.

11. Wüst Zibetti A, Aydi A, Claumann CA, Eladeb A, Adberraba M. Correlation of solubility and prediction of the mixing properties of rosmarinic acid in different pure solvents and in binary solvent mixtures of ethanol + water and methanol + water from (293.2 to 318.2) K. J Mol Liq. 2016;216:370-6.

12. Vilas-Boas SM, Brandão P, Martins MA, Silva LP, Schreiner TB, Fernandes $L$, et al. Solubility and solid phase studies of isomeric phenolic acids in pure solvents. J Mol Liq. 2018;272:1048-57.

13. Pawar RR, Aher CS. Solubility of phenolic compounds in pure water and alcohols with FTIR and DFT study. Int J Sci Res Sci Eng Technol. 2017;3(8):778-90.

14. Shen YZ, Farajtabar A, Xu J, Wang J, Xia YY, Zhao HK, et al. Thermodynamic solubility modeling, solvent effect and preferential solvation of curcumin in aqueous co-solvent mixtures of ethanol, $n$-propanol, isopropanol and propylene glycol. J Chem Thermodyn. 2019;131:410-9.

15. Lan SX, Dong SY, Dong YW. Measurement and correlation of solubilities of trans-Resveratrol in ethanol + water and acetone + water mixed solvents at different temperatures. J Chem Eng Data. 2008;53(11):2562-6.

16. Xiao M, Shao YD, Yan WD, Zhang ZZ. Measurement and correlation of solubilities of apigenin and apigenin 7-O-rhamnosylglucoside in seven solvents at different temperatures. J Chem Thermodyn. 2011:43(3):240-3.

17. Mo F, Ma J, Zhang PP, Zhang DW, Fan HH, Yang X, et al. Solubility and thermodynamic properties of baicalein in water and ethanol mixtures from 283.15 to 328.15 K. Chem Eng Commun. 2019. https://doi. org/10.1080/00986445.2019.1700116.

18. Zhou L, Zhang PP, Yang GD, Lin R, Wang WR, Liu TT, et al. Solubility of chrysin in ethanol and water mixtures. J Chem Eng Data. 2014;59(7):2215-20

19. Wu JG, Ge J, Zhang YP, Yu Y, Zhang XY. Solubility of Genistein in water, methanol, ethanol, propan-2-ol, 1-butanol, and ethyl acetate from (280 to 333) K. J Chem Eng Data. 2010;55(11):5286-8.

20. Shakeel F, Haq N, Alshehri S, Ibrahim MA, Elzayat EM, Altamimi MA, et al. Solubility, thermodynamic properties and solute-solvent molecular interactions of luteolin in various pure solvents. J Mol Liq. 2018;255:43-50.

21. Liu LX, Chen J. Solubility of hesperetin in various solvents from (288.2 to 323.2) K. J Chem Eng Data. 2008;53(7):1649-50.

22. Xu RJ, Cong Y, Zheng M, Chen GQ, Chen J, Zhao HK. Solubility and modeling of hesperidin in cosolvent mixtures of ethanol, isopropanol, propylene glycol, and n-Propanol + water. J Chem Eng Data. 2018;63(3):764-70.

23. Zhang PP, Lin R, Yang GD, Zhang JY, Zhou L, Liu TT. Solubility of naringenin in ethanol and water mixtures. J Chem Eng Data. 2013;58(9):2402-4.

24. Zhang JY, Zhang PP, Liu TT, Zhou L, Zhang LQ, Lin R, et al. Solubility of naringin in ethanol and water mixtures from 283.15 to $318.15 \mathrm{~K}$. J Mol Liq. 2015;203:98-103.

25. Fan JP, Yang D, Xu XK, Guo XJ, Zhang XH. Solubility of daidzin in different organic solvents and (ethyl alcohol + water) mixed solvents. $J$ Chem Thermodyn. 2015;88:85-9.

26. Yang GD, Huang YR, Nan GJ, Chen HJ, Zeng AG, Bian XL. Solubility of daidzein in the binary system of ethanol and water. J Mol Liq. 2013;180:160-3.

27. Alshehri S, Haq N, Shakeel F. Solubility, molecular interactions and mixing thermodynamic properties of piperine in various pure solvents at different temperatures. J Mol Liq. 2018;250:63-70.

28. Yang GD, Li C, Zeng AG, Qu QH, Yang X, Bian XL. Solubility of osthole in a binary system of ethanol and water. Fluid Phase Equilib. 2012:325:41-4.

29. Zeng AG, Zhou J, Li C, Liu YX, Yang X, Yang GD. Solubility, dissolution enthalpy and entropy of isoimperatorin in ethanol + water solvent systems from 288.2 to 328.2 K. J Solution Chem. 2012;41(11):1986-92.
30. Koh GY, Chou G, Liu Z. Purification of a water extract of Chinese sweet tea plant (Rubus suavissimus S. Lee) by alcohol precipitation. J Agric Food Chem. 2009;57(11):5000-6.

31. Pan JJ, Shao JY, Qu HB, Gong XC. Ethanol precipitation of Codonopsis Radix concentrate with a membrane dispersion micromixer. J Clean Prod. 2020;251:119633.

32. Gong XC, Wang SS, Li Y, Qu HB. Separation characteristics of ethanol precipitation for the purification of the water extract of medicinal plants. Sep Purif Technol. 2013;107:273-80.

33. Gong XC, Huang SC, Jiao RN, Pan JY, Li Y, Qu HB. The determination of dissociation constants for active ingredients from herbal extracts using a liquid-liquid equilibrium method. Fluid Phase Equilib. 2016;409:447-57.

34. Li L, Gou JJ, Nan TN, Dan LZ, Yi X. Study on the separation and purification process of emodin from Polygonum cuspidatum. Chin Tradit Patent Med. 2013;35(09):2034-7 (in Chinese)

35. Yang XL, Wang RF, Zhang SP, Zhu WJ, Tang J, Liu JF, et al. Polysaccharides from Panax japonicus C.A. Meyer and their antioxidant activities. Carbohydr Polym. 2014;101:386-91.

36. Wu QN, Luo M, Yao XD, Yu L. Purification, structural characterization, and antioxidant activity of the COP-W1 polysaccharide from Codonopsis tangshen Oliv. Carbohydr Polym. 2020;236:116020.

37. Wei Y, Wang LW, Wang DJ, Wang D, Wen CW, Han BX, et al. Characterization and anti-tumor activity of a polysaccharide isolated from Dendrobium officinale grown in the Huoshan County. Chin Med. 2018;13:47.

38. Feng L, Xiao X, Liu J, Wang JY, Zhang N, Bing T, et al. Immunomodulatory effects of polysaccharide extract and its uptake behaviors at the cellular level. Molecules. 2020;25(6):1351.

39. Xu HL, Liu LL, Chen YX, Ma H, Li M, Qu WS, et al. The chemical character of polysaccharides from processed Morindae officinalis and their effects on anti-liver damage. Int J Biol Macromol. 2019;141:410-21.

40. Chen YW, Li YJ, Zheng MM, Feng KM, Li J, Zhang YQ, et al. Effect of step alcohol precipitation on compositions and antioxidant activity of maca polysaccharide. Chin J Exp Med Formul. 2017;23(18):47-51 (in Chinese).

41. Chen Q, Wu XB, Zhang DQ. Comparison of the abilities of universal, super, and specific DNA barcodes to discriminate among the original species of Fritillariae cirrhosae bulbus and its adulterants. PLOS ONE. 2020;15(2):e0229181.

42. Tao YH, Sun L, Yin HM, Wang XH, Li F, Zhang YJ, et al. Optimization of alcohol precipitation technology of Wubie granules intermediates based on pharmacodynamic screening. Chin J Exp Med Formul. 2016;22(12):28-31 (in Chinese)

43. Luo YH, Li CF, Yang H, Huang KF, Huang YQ. Study on optimizing of the alcohol precipitation refining technology for Yanshuning compound water extract. Fujian Med J. 2010;32(05):71-4 (in Chinese).

44. Zhang Y, Wang YQ, Ma ZY, Mei ZN, Teng HL. Optimization of the water extraction and ethanol precipitation technology of Zhuang Medicine Baijin granules by pharmacodynamics combined with orthogonal test. China Pharm. 2020;31(08):919-25 (in Chinese).

45. Zhang L, Liu JT. Optimization of alcohol precipitation technology for dingtongning granule based on index components and pharmacodynamics. China Pharmacist. 2017;20(11):1979-82 (in Chinese)

46. Hua JL, Ding YF, Ju JM, Lu M, Li SL, Shen MQ, et al. Optimization of alcohol precipitation technology of changkang granules based on index components and pharmacodynamics. Chin J Exp Med Formul. 2014;20(4):16-9 (in Chinese)

47. Luo ZS, Qian ZY, Zhou M, Huang XP, Gui SS, Tan RG. Optimization of extraction technology and precipitation process for Eryan Huguo decoction by orthogonal test. Chin Tradit Patent Med. 2016;38(01):193-7 (in Chinese).

48. Leng J, Guo XH, Xu C, Tian FW, Yang M. Optimization of water extraction and alcohol precipitation of Xikebao decoction and comparison of anti-inflammatory and analgesic effects. Chin Tradit Patent Med. 2017;39(01):191-5 (in Chinese).

49. Zhou YQ, Liu SF, Zhang N, Wang YJ, Du SM. Optimization of purification technology for Shenqi Sherong pills by chemical and pharmacodynamic indicators. Chin J Exp Med Formul. 2013;19(06):36-9 (in Chinese) 
50. Yan HY, Zou CC, Huang L, Jin Y. A comparative study on efficacy of Gualou-Xiebai extracts in different alcohol precipitation oncentration. Chin Hosp Pharm J. 2014;34(23):1973-7 (in Chinese).

51. Jin SY, Cui RQ, Zhang F, Cao Y. Optimization of alcohol precipitation for Lidan Paidu prescription based on index compotents and pharmacodymamics. Cent South Pharm. 2017;15(09):1233-7 (in Chinese).

52. Xia BH, Liu JY, Li C, He YC, Liang H, Gong LM, et al. Anti-hypertensive effect of aqueous extract and supernatants of alcohol extractingwater precipitation of Prunella vulgari. Chin J Exp Med Formul. 2014;20(2):113-6 (in Chinese)

53. Su Q, Wu TT, Huang YL, Ling BD, Wu CJ. Research on changes of composition and efficacy of Scutellariae radix extract in process of preparation. Chin J Exp Med Formul. 2018;24(14):1-6 (in Chinese).

54. Zhang FS, Ran CX, Zheng J, Ding YB, Chen GJ. Polysaccharides obtained from bamboo shoots (Chimonobambusa quadrangularis) processing by-products: new insight into ethanol precipitation and characterization. Int J Biol Macromol. 2018;112:951-60.

55. Du ZC, Qi B, Zhang MZ, Wei YX, Li LJ, Hao EW, et al. Optimization of extraction technology of Guizhi Zhumian Capsule by orthogonal design and pharmacodynamics test. China Tradit Herb Drugs. 2019;50(03):618-25 (in Chinese).

56. Zheng X. Chinese Medicine Pharmaceutical Engineering and Technology. Shang Hai: East China University of Science and Technology Press; 2008 (in Chinese).

57. Wang Q. Talking about ethanol precipitation technology and equipment of Chinese medicine. Mechanical and Electrical Information. 2009;32:38-40 (in Chinese)

58. Gong XC, Shen JC, Qu HB. Application of continuous mixing technology in ethanol precipitation process of Salvia miltiorrhiza by using micromixer. China J Chin Materia Med. 2016;41(23):4356-61 (in Chinese).

59. Yu HS, Bie ST, Li Z, Song XB, Li ZL, Liu CQ, et al. Device and method of alcohol precipitation in pressure type mechanical atomization combination continual alcohol precipitation patent. CN106512477A. 2016-12-29.

60. Yan BX, Zhang JA, Zhang AC, Zhou SQ, Fu ZS, Fan YL. Ethanol Precipitation Tank patent. CN202983296U. 2012-10-31.

61. Zhao ZY. Ethanol settling tank with efficient stirring device patent. CN204182170U. 2014-10-24.

62. Shen $Y H$, Xiang GG, Xiang ZL, Shen YC, Dong XH, Dai LY, et al. Efficient Ethanol Precipitation Tank patent. CN201768402U. 2010-07-22.

63. He GY, Zhou MD, Tong SQ, Qu HB, Yan JZ. Optimizing process of radix salvia miltiorrhiza ethanol precipitation by response surface methodology. Chin JMAP. 2010;27(02):118-22 (in Chinese).

64. Yuan J, Li YR, Chen Y, Wang LH, Liu XS. Optimization of alcohol precipitation process of Salviae miltiorrhizae water-extraction solution by orthogonal design with multi-index comprehensive evaluation. Chin $J$ Pharms. 2010;41(11):826-9 (in Chinese)

65. Gong XC, Yan BJ, Qu HB. Correlations of three important technological parameters in first ethanol precipitation of Danshen. China J Chin Materia Med. 2010;35(24):3274-7 (in Chinese)

66. Hu XY, Li YR, Yuan J, Liu XS, Chen Y, Zhang AY. Optimization of alcohol precipitation process of Cinobufacini extract by multi-index comprehensive evaluation method. Lishizhen Med Mater Med Res. 2012;23(04):1016-9 (in Chinese)

67. Hou LZ, Zhang XJ, Wang Y, Liu XH. Orthogonal test for optimizing ethanol precipitated technique of Kuanxin oral liquor. Chin J Exp Med Formul. 2011;17(02):32-4 (in Chinese)

68. Zhang L, Gong XC, Qu HB. Optimizing the alcohol precipitation of Danshen by response surface methodology. Sep Sci Technol. 2013;48(6):977-83.

69. Yan BJ, Guo ZT, Qu HB, Zhao BC, Zhao T. An approach to determine critical process parameters for ethanol precipitation process of Danhong injection. China J Chin Materia Med. 2013;38(11):1672-5 (in Chinese)

70. Yan BJ, Guo ZT, Qu HB, Zhao BC, Zhao T. Feedforward control strategy and its application in quality improvement of ethanol precipitation process of Danhong injection. China J Chin Materia Med 2013;38(11):1667-71 (in Chinese)

71. Zhang L, Yan BJ, Gong XC, Lawrence XY, Qu HB. Application of quality by design to the process development of botanical drug products: a case study. AAPS PharmSciTech. 2013;14(1):277-86.
72. Zhong Y, Zhu JQ, Fan XH, Kang LY, Li Z. Network analysis of ethanol precipitation process for Schisandrae Chinensis Fructus. China J Chin Materia Med. 2014;39(17):3287-90 (in Chinese).

73. Gong XC, Yan AY, Qu HB. Optimization for the ethanol precipitation process of botanical injection: indicator selection and factor influences. Sep Sci Technol. 2014;49(4):619-26.

74. Gong XC, Li Y, Guo ZT, Qu HB. Control the effects caused by noise parameter fluctuations to improve pharmaceutical process robustness: a case study of design space development for an ethanol precipitation process. Sep Purif Technol. 2014;132:126-37.

75. Yi YD, Ma W, Lin SH, Yu NC. Optimization of alcohol precipitation technology for Qingmai granules by orthogonal test. China Pharmacist. 2014;17(04):571-3 (in Chinese).

76. Bi HS, Guo JG, Xie XF. Optimization of water extraction and alcohol precipitation process for Gardeniae Fructus by orthogonal design. Chin J Exp Med Formul. 2014;20(1):19-23 (in Chinese).

77. Chen C, Wu XY, Huang YZ, Gong MY, Mo XL, Huang QF. Optimization of water extraction and alcohol precipitation technology for hemorrhoid fumigants by orthogonal test. Chin J Exp Med Formul. 2014;20(17):16-9 (in Chinese).

78. Chen LH, Zhang QH, Guan YM, Zhu WF, Yang M, Cheng L, et al. Optimization of alcohol precipitation process for extra-cellular polysaccharides from fermentative fluid of cordyceps. Chin J Exp Med Formul. 2014;20(18):20-2 (in Chinese).

79. He YH, Xie YB, Su XL, Li HB, Wu AM, Wu J, et al. Optimization of alcohol precipitation technology for safflower injection with orthogonal test method. Pharm J Chin PLA. 2014;30(4):321-3 (in Chinese).

80. Li YW, Wen DD, Zhang XJ. Optimization of extraction technology of ephedran. China Pharmaceuticals. 2014;23(19):49-52 (in Chinese).

81. Nong $Y Q, X u M H$, Jiang L. Optimization of water extraction and alcohol precipitation process of Lanshen Lipidlowering prescription by orthogonal test. Food and Drug. 2014;16(2):88-91 (in Chinese).

82. Wang CY, Yang JC, Li YX, Ma CW. Optimization of ethanol precipitation technique for Fufang Shenqi soft capsules by orthogonal design. China Pharmacist. 2014;17(5):773-5 (in Chinese).

83. Xu ZL, Huang WH, Gong XC, Ye TT, Qu HB, Song YG, et al. Design space approach to optimize first ethanol precipitation process of Dangshen. China J Chin Materia Med. 2015;40(22):4411-6 (in Chinese).

84. Yan M, Wei YC, Li XF, Meng J, Wu Y, Xiao W. Optimization on alcohol precipitation techniques of Liuwei Dihuang decoction by response surface methodology. China J Chin Materia Med. 2015;40(19):3794-9 (in Chinese)

85. Gao X, Qin J, Zhang WJ, Qi JJ, Hou YF, Qi L, et al. Optimization of water-extracting and alcohol precipitating conditions of total polysaccharides from Trillium tschonoskii Maxim. Northwest Pharm J. 2015;30(05):562-6 (in Chinese).

86. Liu WX, Yang X, Weng ZP, Wang JZ, Tang PL, Zhao Y. Research on alcohol precipitation technology of LW-PSB. Lishizhen Med Mater Med Res. 2015;26(03):608-10 (in Chinese).

87. Shi H, Bai J, Feng X, Wang LY, Ma Q. Optimization of water extraction and alcohol precipitation technology for Qiguiyin formula with multiindex. Chin Archives Tradit Chin Med. 2015;33(04):813-6 (in Chinese).

88. Wang YX, Mi H-J, Zhang CL, Hu Y, Shi J, Bi YA, et al. Optimization on alcohol precipitation process for Lonicerae Flos and Artemisiae Annuae Herba in Reduning Injection by central composite design and response surface methodology. China Tradit Herb Drugs. 2015;46(05):671-8 (in Chinese).

89. Yuan J. Optimization of Water extract and alcohol precipitation process of Bishuang Paidu granules by orthogonal test. China Pharmaceuticals. 2015;24(18):59-61 (in Chinese).

90. Hou YD. Optimization of Alcohol precipitation process for tannins in Herba Sarcandrae. Strait Pharm J. 2015;27(4):39-42 (in Chinese).

91. Pan Y. Study on the water extraction and alcohol precipitation technology of polysaccharide from Zizyphus jujube CV. Dongzao. The Food Industry. 2015;36(1):124-6 (in Chinese).

92. Xi ZJ, Xu LW, Shi XF, Qi W, Tao JS, Yuan CX. Study on the preparation process of Zhenjing Xiehuo granules. China Pharmacist. 2015;18(12):205861 (in Chinese)

93. Chen HW, Zhang CY, Ren WG, Wang J, Wei BJ. Multi-index integrated evaluation method optimizes water.extraction and ethanol 
precipitation of Xuanbi antong formula (XBF). China J Chin Materia Med. 2016;41(01):70-4 (in Chinese).

94. Chen LY, Wang LC, Wu H, Cheng JM, Liu R, Chai Y, et al. Optimization of extraction technology and alcohol precipitation process for watersoluble polysaccharides in Meretrix meretrix by orthogonal test. Chin J Exp Med Formul. 2016;22(05):18-21 (in Chinese).

95. Huang XO, Wei YL, Lan XQ. The alcohol precipitation technology research of Guben Bushen oral liquid. Chin Med J Res Prac. 2016:30(02):38-40 (in Chinese).

96. Li Q, Liang XM, Du HF, Zhou X, Wang Y, Guo JH. Optimization of water extraction and alcohol precipitation technology of Tongfengxiao granules by orthogonal test. China Pharm. 2016;27(04):518-21 (in Chinese).

97. Li RH, Sun ZT, Lu ZG, Wang YX, Li Y, Liu ES, et al. Optimization of ethanol precipitation process of Zhimahuang Group in Shufeng Dingchuan granules by analytic hierarchy process and entropy method. Chin J Exp Med Formul. 2016:22(20):1-5 (in Chinese)

98. Shao J, Sun ZH, Guo M, Zhao ZJ, Wen XY. Optimization of ethanol precipitation process for total polysaccharides extracted from Shenqi compound recipe by Box-Behnken design combined with response surface methodology. Chin J Pharms. 2016;47(8):1012-5 (in Chinese).

99. Xue D, Ni J, Zhang P, Yang CJ, Zhao Y, Xia ZW, et al. Optimization of aqueous extraction-alcohol precipitation technology for Qifang Bimin granules with multi-index orthogonally designed experiments. Tianjin J Tradit Chin Med. 2016:33(01):39-42 (in Chinese)

100. Yu W, Yang HL, Zhou HB, Zhou YP. Orthogonal test for optimizing ethanol precipitated technique of Bazhen granules. Chin J EthoMed Ethnopharm. 2016;25(09):28-9 (in Chinese).

101. Zhang Q, Pu WY, Qian F. Optimization of water extraction and alcohol precipitation technology for Qianyang Yuyin granules by orthogonal test. Chin J Inf Tradit Chin Med. 2016;23(12):103-6 (in Chinese).

102. Zhang YJ, Liu LL, Chang XJ, Wu Y, Xiao W, Hu JH, et al. Optimization of alcohol precipitation technology of Biqiu granules based on index components and pharmacodynamics. China J Chin Materia Med. 2016:41(24):4598-604 (in Chinese).

103. Li L, Yang J, Long XY, Li ZJ, Wang SY, Sun JZ. Optimization of the extraction process of Chailing Hugan granules. J Guangdong Pharm Univ. 2016;32(6):695-9 (in Chinese)

104. Liu PA, He Q, Li SX, Xie Y, Chen GY, Cai GX. Study on preparation process of Dendrobium Candidum eye drops. China Pharmacist. 2016;19(1):73-7 (in Chinese).

105. Pan HY, Deng HX, Chen ZQ, Zhang YF, Wang LH. Study on balance of process of alcohol precipitation of ganmaoling granules. China J Chin Materia Med. 2016;41(8):1376-9 (in Chinese)

106. Wan L. Process optimization on water extract-alcohol extraction of Majiezhike granules. China Pharmaceuticals. 2016;25(7):8-10 (in Chinese)

107. Chen CY, Qian F. Optimization of water extraction and alcohol precipitation technology for Shouwu Granula by orthogonal test. Chin Med J Res Prac. 2017;31(01):37-40 (in Chinese)

108. Li YZ, Wen YD, Yu J, Peng PJ, Yang XJ. Optimization of alcohol precipitation process for Qingyan Shuanghou granules using Box-Behnken design-response surface methodology. Hunan J Tradit Chin Med. 2017:33(06):165-7 (in Chinese)

109. Shuai XC, Wang T, Xu FF. Optimization of ethanol precipitation process for Liqifuwei oral liquid by orthogonal test. Pract J Clin Med. 2017;14(06):110-2 (in Chinese)

110. Zhang GH, Wang J, Chen JS, Duan WJ, Ma YS. Optimization of water extraction and alcohol precipitation technology of Tong Fengqing cataplasm. Lishizhen Med Mater Med Res. 2017;28(12):2918-21 (in Chinese)

111. Zhang X, Ni J, Zhang LL, Zhang J, Wang HT, Li R, et al. Optimization of water extraction and alcohol precipitation technology for Zhidanhuayu formula with multi-index. Chin Med J Res Prac. 2017;31(01):44-8 (in Chinese)

112. Chen XT, Xu WJ, Li ZY, Wang LL. Optimization of extraction technology and precipitation process for Chaixiong mixture by orthogonal test. Pharm Today. 2017;27(4):225-7 (in Chinese)

113. Fang $Y$, Zhao YY, Liu YH, Xu FQ, Jin CS, Wu DL, et al. Study on extraction technology of polysaccharides from Poria Cocos. Acta Chin Med. 2017:32(4):602-5 (in Chinese).
114. Zhang SY, Song XL, Liu W, Tang J, Shi HZ. Water extract-alcohol precipitation process of dibutyl particles. J Anhui Agri Sci. 2017;45(29):3-5 (in Chinese).

115. Fan L, Luo JZ, Gu XQ, Gu QH, Yu DW. Study on the water extraction and alcohol precipitation technology in tegrated of Xuanfei Zhike Granule. China Pharmacist. 2018;21 (01):93-6 (in Chinese).

116. Han SS, Luo SW, Chen LX, Wang YY. Study on the water extraction and alcohol precipitation of compound Cornu Cervi Degelatinatum. Bachu Med J. 2018:1(02):71-5 (in Chinese)

117. Wan DN, Rao QR, Yu MY, Liu RH, Quan HX, Yang M, et al. Optimization of ethanol precipitation technology of Crataegus pinnatifida by using Box-Behnken design-response surface methodology. China Pharm. 2018;29(15):2078-81 (in Chinese).

118. Wang WP, Ni J, Leng X, Yang CJ, You LT, Liu Y, et al. Optimization of water extraction and alcohol precipitation process of Qizhi Yifei granules by multi-index orthogonal experimental. Chin J Inf Tradit Chin Med. 2018;25(09):71-5 (in Chinese)

119. Lan H, Zuo Q, Yang J, Liu T, Bin J. The research on water extraction and alcohol precipitation process of Qingyan Oral Liquid. Chin J EthoMed Ethnopharm. 2018:27(6):17-21 (in Chinese)

120. Liu XL, Cai XH, Ni XX, Wang QF, Chen JS. Optimization on alcohol precipitation process of compound Yinchen mixture by central composite design-response surface method. J Pharm Pract. 2018;36(4):329-33 (in Chinese).

121. Zhu ZD, Luo YD, Xiao M, Tan AQ, Li FC. Study on the alcohol precipitation and drying process of Shiwei Ehuang Granules. China Modern Med. 2018;25(25):11-5 (in Chinese).

122. Kang YP. Study on water extraction and alcohol precipitation technology for Weibikang Granule. Chin Med Modern Distance Education of China. 2019;17(13):116-8 (in Chinese)

123. Cong J, Wang XL. Optimization of ethanol precipitation process of Panax Ginseng and Pueraria Lobata concentrated decoction by response surface method. China Pharm. 2019;28(16):17-9 (in Chinese)

124. Ma XT, Xiao FQ, Qiu MY, Wang TN, Yan MM, Yi CG, et al. Optimization of water extraction andethanol precipitation process and activity of compound lipid-lowering sustained-release tablets by multi-index comprehensive scoring method. Chin J Hosp Pharm. 2019;39(17):175965 (in Chinese).

125. Qin H. Optimazation of water extraction and alcohol precipitation total alkaloid in Sophora flavescens by star point design-response surface method. Mod Chin Med. 2019;21(08):1084-8 (in Chinese).

126. Wang LH, He XH, Ma T, Tian PP, Li J, Chen HW. Optimization of water extraction and alcohol precipitation process and improvement of cardiac function in rats with myocardial infarction (stasis-heat syndrome) for GCRF formula. Chin J New Drugs. 2019;28(07):862-70 (in Chinese).

127. Wang YL, Shang RG, Li KL, Dou JW. Optimization of alcohol precipitation process of Kangzhi suppository by orthogonal test. World Chin Med. 2019;14(06):1378-81 (in Chinese).

128. Zhu Y, Yu SR, Zhang XY, Zhou C, Wei J. Optimization of alcohol-precipitation technology for Fufang Roucongrong Mixture by AHP combined with orthogonal test. China Pharmacist. 2019;22(07):1257-60 (in Chinese)

129. Li BS, Kang Q, Chen C, Wang YJ, Zhao Y, He BY, et al. Optimization of alcohol precipitation technology for Fufang Shuanghua oral liquid based on FAHP-entropy method. Central South Pharm. 2019;17(3):414-9 (in Chinese)

130. Sun MF, Yang JY, Cao W, Shao JY, Wang GX, Qu HB, et al. Critical process parameter identification of manufacturing processes of Astragali Radix extract with a weighted determination coefficient method. Chin Herb Med. 2020;12(02):125-32.

131. Zhang H, Yan AY, Gong XC, Qu HB. Study on quality indicators for concentration process of supernatant obtained in first ethanol precipitation in production of Danshen injection. China J Chin Materia Med. 2011;36(11):1436-40 (in Chinese)

132. Yan AY, Gong XC, Qu HB. Method for discriminating key quality control indicators of concentrated solution before traditional Chinese medicine ethanol precipitation. China J Chin Materia Med. 2012;37(11):1558-63 (in Chinese)

133. Shah HK. Impact of Correlated Responses on the Desirability function. Bachelor's thesis. Arizona State University, 2001. 
134. International Conference on Harmonization of Technical Requirements for Registration of Pharmaceuticals for Human Use (ICH). Pharmaceutical development. Q8 (R2). 2009. https://database.ich.org/sites/default/ files/Q8_R2_Guideline.pdf. Accessed 21 Apr. 2020.

135. Shao JY, Qu HB, Gong XC. Comparison of two algorithms for development of design space-overlapping method and probability-based method. China J Chin Materia Med. 2018;43(10):2074-80 (in Chinese)

136. Zhao F, Gong XC, Qu HB. Optimization of ethanol reflux extraction process of red ginseng using a design space approach based on hazard and operability analysis. China J Chin Materia Med. 2017;42(06):1067-73 (in Chinese).

137. Wang J. Application of process analysis technology in Salvia miltiorrhiza ethanol precipitation and'Yang Wei'Granules spraying. Bachelor's thesis. Zhejiang University, 2007.

138. Luo XF. Application of statistical process control in quality control of Danshen Injection. Bachelor's thesis. Zhejiang University, 2008.

139. Liu B, Bi KS, Sun L, Shi XY, Qiao YJ, Liu ZQ. Determining Danshensu and Hesperidin in Rukuaxiaopian using near-infrared spectroscopy. World Sci Technol/Modern Tradit Chin Med Materia Med. 2009;11(03):388-94 (in Chinese)

140. Xing LH, Xu JZ, Qu HB. Rapid near-infrared spectroscopy determination of tannins in the alcoholic-precipitation process of Radix Salviae Miltiorrhizae. Chin J Pharm Ana. 2010;30(10):1813-6 (in Chinese).

141. Huang HX, Qu HB. In-line monitoring of alcohol precipitation by nearinfrared spectroscopy in conjunction with multivariate batch modeling. Anal Chim Acta. 2011;707(1):47-56.

142. Sun D, Yuan J, Hu XY, Liu XS. Fast analytical method on content and transfer rate of marker component in ethanol precipitation of cinobufacini by near infrared spectroscopy. China J Chin Materia Med. 2011;36(18):2479-83 (in Chinese)

143. Xu B, Shi XY, Qiao YJ, Du M, Sui CL, Liu Q. Multi-phase and multivariate statistical process control for alcohol precipitation of water extract of Lonicerae Japonicae. Chin J Tradit Chin Med Pharm. 2012;27(04):784-8 (in Chinese).

144. Wu ZS, Xu B, Du M, Sui CL, Shi XY, Qiao YJ. Validation of a NIR quantification method for the determination of chlorogenic acid in Lonicera japonica solution in ethanol precipitation process. J Pharmaceut Biomed. 2012;62:1-6.

145. Xu B, Wu ZH, Lin ZZ, Sui CL, Shi XY, Qiao YJ. NIR analysis for batch process of ethanol precipitation coupled with a new calibration model updating strategy. Anal Chim Acta. 2012;720:22-8.

146. Jin Y, Wu ZZ, Liu XS, Wu YJ. Near infrared spectroscopy in combination with chemometrics as a process analytical technology (PAT) tool for on-line quantitative monitoring of alcohol precipitation. J Pharmaceut Biomed. 2013;77:32-9.
147. Wang YX, Mi HJ, Wang ZZ, Zhang CL, Su G, Xiao W. Near infrared spectroscopy on-line and real - time monitoring of alcohol precipitation process of Reduning Injection. China J Chin Materia Med. 2014;39(23):4608-14 (in Chinese)

148. Du WJ, Liu XS, Tao LY, Jin Y, Chen Y, Wu S, et al. Multi-indicators rapid determination in alcohol precipitation of Lonicerae Japonicae Flos and Artemisiae Annuae Herba in Reduning Injection by near-infrared spectroscopy. China Tradit Herb Drugs. 2015;46(01):61-6 (in Chinese).

149. Li TT, Hu T, Nie L, Zang LX, Zeng YZ, Zang HC. Rapid monitoring five components of ethanol precipitation process of Shenzhiling oral solution using near infrared spectroscopy. China J Chin Materia Med. 2016;41(19):3543-50 (in Chinese)

150. Luo Y, Li WL, Huang WH, Liu XH, Song YG, Qu HB. Rapid quantification of multi-components in alcohol precipitation liquid of Codonopsis Radix using near infrared spectroscopy (NIRS). J Zhejiang Univ Sci B. 2017;18(5):383-92.

151. Luo Y. Studies on the quality control of alcohol precipitation process of Shenqi Fuzheng Injection using near infrared spectroscopy. Bachelor's thesis. Zhejiang University, 2017.

152. Huang HX, Qu HB. In-situ monitoring of saccharides removal of alcohol precipitation using near-infrared spectroscopy. J Innov Opt Heal Sci. 2018;11(05):1850027.

153. Yan X, Fu H, Zhang S, Qu HB. Combining convolutional neural networks and in-line near-infrared spectroscopy for real-time monitoring of the chromatographic elution process in commercial production of notoginseng total saponins. J Sep Sci. 2020;43(3):663-70.

154. Yan X, Fu H, Zhang S, Qu HB. Combining convolutional neural networks and on-line Raman spectroscopy for monitoring the Cornu Caprae Hircus hydrolysis process. Spectrochim Acta Part A Mol Biomol Spectrosc. 2020;226:117589.

155. Yan BJ, Li Y, Guo ZT, Qu HB. Quality by design for herbal drugs: a feedforward control strategy and an approach to define the acceptable ranges of critical quality attributes. Phytochem Anal. 2014;25(1):59-65.

\section{Publisher's Note}

Springer Nature remains neutral with regard to jurisdictional claims in published maps and institutional affiliations.

Ready to submit your research? Choose BMC and benefit from:

- fast, convenient online submission

- thorough peer review by experienced researchers in your field

- rapid publication on acceptance

- support for research data, including large and complex data types

- gold Open Access which fosters wider collaboration and increased citations

- maximum visibility for your research: over 100M website views per year

At BMC, research is always in progress.

Learn more biomedcentral.com/submissions 